\title{
Does financial behavior mediate the relationship between self-control and financial security?
}

\author{
Marija Vuković ${ }^{1 *}$ and Snježana Pivac ${ }^{1}$ \\ 1 University of Split, Faculty of Economics, Business and Tourism, \\ Cvite Fiskovića 5, 21000 Split, Croatia \\ E-mail: 〈\{mvukovic, spivac\}@efst.hr $\rangle$
}

\begin{abstract}
People have different financial behavior depending on their psychological characteristics, which can reflect their financial security. Self-control is also an important predictor of financial security. People with greater self-control are more likely to save money and less likely to get into debt. Therefore, they are more secure and satisfied with their financial situation. This paper explores whether good self-control directly affects financial security or if its impact comes indirectly through good financial behavior. For the purposes of the research, a survey analysis was designed and applied to a sample of 494 respondents. Structural equation modeling was used for testing the research hypothesis. The results confirmed that there is a significant mediating effect of financial behavior on the relationship between self-control and financial security. The research contributes to a better understanding of financial behavior predictors among individuals with different psychological characteristics. Future research should also include testing for differences between various demographic groups of people in the impact of self-control on financial behavior and security.
\end{abstract}

Keywords: financial behavior, financial security, self-control, structural equation modeling

Received: September 25, 2020; accepted: February 10, 2021; available online: June 29, 2021

DOI: $10.17535 /$ crorr.2021.0003

\section{Introduction}

Financial well-being can be subjectively evaluated by people's attitude towards their financial situation. People can feel more or less anxious or secure about their own financial decisions, which are influenced by their specific financial behavior [18]. Individuals differ in their habits and their behaviors. While some people show good and disciplined financial behavior, other people make poor financial decisions, which consequently leads them to less financial security. Their behavior depends on multiple factors, such as psychological characteristics, financial literacy, demographic characteristics, and self-control [14, 20, 23]. Self-control is significant in many areas of life, and it is an important predictor of financial security. It can be defined as "sacrificing short-term outcomes in favor of long-term outcomes" [6]. In the context of financial behavior, people with greater self-control are more likely to save money and less likely to get into debt. Therefore, they are more secure and satisfied with their financial situation.

This paper explores whether good self-control directly affects financial security or if its impact comes indirectly through good financial behavior. The research hypothesis states that financial behavior mediates the relationship between self-control and financial security. For the purposes of the research, a survey analysis was designed according to previous research $[15,20]$ and applied to a sample of 494 respondents in Croatia. The research contributes to a better understanding of financial behavior predictors among individuals with different psychological

* Corresponding author. 
characteristics. It is important for the individuals themselves to understand what the underlying cause of their certain financial decisions is in order to improve them and achieve better financial security. It can also be learned if there are differences in the predictors of financial behavior and financial security in Croatia compared to other countries. Since there is not much research to our knowledge that explores the effect of self-control on financial security, this research contributes to the scientific literature with new findings, expanding the conclusions of Strömbäck et al. [20].

The structure of the paper includes an introduction, followed by a theoretical framework and literature review. Afterwards, the research methodology and data are presented and described. Then, the results of the empirical analysis are provided and discussed. Lastly, a conclusion is given along with future research recommendations.

\section{Theoretical framework and literature review}

The financial decisions of individuals influence their subjective attitude towards their present and future financial security. People are primarily different in their demographic characteristics. In addition to that, individuals are unique in relation to their psychological characteristics, such as personality, optimism, intuitiveness, etc. In the context of financial behavior, people's ability to make quality decisions is important. This is directly influenced by these aforementioned psychological characteristics, but also by individual self-control [15, 20].

Self-control is "the ability to resist urges and self-regulate unwanted behavioral impulses" [21]. It forces an individual to sacrifice short-term outcomes in favor of long-term outcomes [6]. In financial decision-making, self-control is known to be an important psychological resource for controlling compulsive buying and the tendency to get into debt $[2,12]$. People should recognize if they face a control problem and understand how it affects their choices, since their ability to control impulses is a crucial factor for success in many areas of life, including financial decision-making $[4,20]$. In this context, self-control can be seen as financial control, which refers to the managing of an individual's revenues and expenses [12]. Shefrin and Thaler [18] stated that self-control is incorporated into the behavioral life cycle (BLC) hypothesis and it is more or less costly depending on people's mental accounts and [3] stated that control skills are important in monitoring the patterns of spending. They also suggested that these skills are the underlying cause of the propensity to plan. The self-control of buying urges was examined through an experiment, which proved that impulsive behavior can be reduced over time when exercising self-control improvement [24]. Strömbäck et al. [20] explored the impact of selfcontrol on financial behavior and financial well-being in Sweden. They found that people with high self-control have better financial behavior and that they were less anxious and more secure about their financial situation. Younas et al. [28] conducted similar research in Pakistan, where they analyzed the impact of self-control and financial literacy on financial well-being. They concluded that self-control has no direct impact on financial well-being. Instead, they stated that the impact is indirect. On the other hand, other research [19] found that self-control mediated a partial effect of financial knowledge and financial attitudes on financial management behavior. Financial behavior was also found to be positively influenced by financial attitude and self-control [10].

In addition to self-control, other non-cognitive factors also influence financial behavior. Behavioral heterogeneity should be considered when exploring financial behavior. Namely, individuals are unique according their personality, preferences, attitudes, emotional stability, etc. Parise and Peijnenburg [16] concluded that people with lower non-cognitive abilities tend to make poorer financial decisions, thereby decreasing financial security. Another psychological trait, which can greatly influence financial behavior, is optimism. Optimistic people are more prone to saving, they work harder and retire later. On the other hand, depressed individuals are more pessimistic about all aspects of the future [20, 22]. In addition, other research [3] found that people with financial planning skills, monitoring abilities, and budgeting skills will be 
more successful in overcoming problems with poor financial decisions, such as excessively high spending. This can be seen as deliberative thinking, which can be described as a more effortful, explicit, and consciously controlled process. This kind of behavior can be found more often with professional financial traders rather than non-professional financial traders [15, 26]. Opposed to deliberativeness, intuition or intuitive thinking is often an emotionally charged process, which is effortless and implicit [15]. One study [20] found a positive influence of optimism and deliberative thinking on financial behavior. Another [15] concluded that decision domains determine whether an individual is going to rely more on intuitiveness or deliberativeness in decision-making.

To summarize, self-control has been found to have a positive impact on financial behavior. This means that people with more self-control are better at managing their finances, not engaging in compulsive buying, and not getting into debt [2, 3, 4, 6, 10, 12, 18, 19, 20, 21, 28]. Besides self-control, some other psychological factors have been found to influence financial behavior. The focus of this research is on non-cognitive factors, which reflect self-reported measures of personal preferences, personality behavior, thoughts, and feelings, instead of analyzing cognitive abilities, which can be numerically measureable $[16,20]$. This research considers several noncognitive factors as predictors of financial behavior. These factors, in addition to self-control, are optimism, deliberativeness, and intuitiveness. There is not much research connecting selfcontrol with financial security. Therefore, relying on the research of Strömbäck et al. [20], this study aims to obtain a better understanding of their findings by investigating if this impact of self-control on financial security is direct or if it comes indirectly through good financial behavior, which is the primary aim of the research. Secondly, this research provides an insight into additional non-cognitive factors, such as potential predictors of financial behavior, thus extending the research model of Younas et al. [28].

Considering the research goal, the following research hypothesis is proposed:

H1. Financial behavior mediates the relationship between self-control and financial security.

\section{Methodology}

\subsection{Research instrument}

For the purpose of conducting the research, a survey questionnaire, based on previous studies, was designed and applied. The research was carried out in the period of October to December 2019. The survey questionnaire was distributed in electronic form via social networks and email in order to collect data from a random sample of respondents. It consists of several parts. The first part of the survey refers to the socio-demographic characteristics of individuals. The second part of the survey refers to financial planning and financial management, while the last part of the survey encompasses questions regarding self-control and the socio-emotional traits of individuals.

In the group of questions about financial planning and financial management, there are six questions regarding financial behavior and three questions representing attitudes towards one's financial security. These questions were based on previous research [20]. In the last part of the survey, there are six questions representing self-control, three questions on optimism, and four questions for both deliberative thinking and intuitiveness. This group of questions was formed according to [15] and [20]. The answers to the questions from the survey regarding the respondents' agreement with certain statements which measure different concepts of interest, were formulated as a 1-5 Likert scale ( $1=$ strongly disagree, $5=$ strongly agree), as formulated in their previous applications. The scale for self-control and optimism was reversed, due to the nature of the questions and the hypothesized relationships in the research model. 


\subsection{Data}

The research focuses on Croatian residents of all age groups. Data was collected through random sampling, since each person had an equal chance of being included in the sample, and the selections of people were made independently [25]. The final sample includes 494 respondents. There is no missing data.

The sample includes $37 \%$ male respondents and $63 \%$ female respondents. The average age of the respondents is 37.31 years, while the median age is 35 years. Most of the respondents are highly educated. $26.3 \%$ of the respondents had finished high school or a lower level of education, while half of the sample $(50.4 \%)$ had finished undergraduate study or a lower level of education. The average income of the respondents is 7576.28 kunas, while the median income is 6200 kunas.

\subsection{Statistics}

The data collected through the survey was analyzed by using the statistical packages SPSS 23.0 and Mplus 7. Convergent validity was tested using the average variance extracted to "measure the convergence among a set of items representing a latent construct" [8]. Discriminant validity was tested according to the Fornell and Larcker criterion, in order to check "the extent to which a construct is truly distinct from other constructs in the model" [8, 29]. Additionally, Cronbach's alpha coefficients were calculated for the reliability analysis in order to "determine the extent to which the variables are consistent in their values" [8]. To test the research hypothesis, the structural equation modeling (SEM) was used. SEM is an appropriate method, since the research model consists of multiple causal relationships between latent constructs and it can test the significance of both direct and indirect effects. Therefore, by using SEM, it is possible to test for mediation, i.e. the effect of an intervening variable or a construct between two other related constructs [8], which is the primary goal of this research.

SEM "enables the simultaneous examination of a series of interrelated dependence relationships between the measured variables and latent constructs, as well as between several latent constructs" [8]. Latent constructs cannot be directly observable. Instead, they are measured by one or multiple indicators. These indicators are known as "measured (observed, manifest) variables, whose scores are collected and entered in a data file" [8, 11]. SEM analysis includes two steps. The first step is to develop a measurement model, to specify the indicators for the constructs, and to enable an assessment of construct validity. If the measurement model shows good fit, the next step is to specify a structural model, which represents "a set of one or more dependence relationships between the latent constructs" [8]. This research uses several latent constructs: financial security, financial behavior, self-control, optimism, deliberative thinking, and intuitiveness. The exogenous constructs in the model are self-control, optimism, deliberative thinking, and intuitiveness. Financial behavior and financial security are endogenous constructs, where financial behavior is also a mediating construct. As already mentioned, all of these constructs are measured via several variables, i.e. the corresponding questionnaire items.

Even though SEM has plenty of advantages compared to other methods, it also has its flaws. Namely, "SEM analysis should have a strong theoretical base, but sometimes researchers just look for statistically significant results, without sufficient theoretical justification of their model" [17]. Therefore, "post hoc model tuning" in SEM may result in senseless models [13].

A path diagram for the proposed theoretical model is shown in Figure 1. 


\section{Empirical results and discussion}

\subsection{Validity and reliability analysis}

According to the two-step modeling approach in SEM analysis, it is first necessary to assess construct validity and reliability. Construct validity measures the extent to which the indicators actually represent the latent construct and it is explored through convergent and discriminant validity. Convergent validity measures the convergence among a set of items representing a latent construct and it was tested with average variance extracted (AVE), while discriminant validity tests if a construct is truly distinct from other constructs. Testing for discriminant validity was conducted according to the Fornell and Larcker criterion. Furthermore, reliability analysis was used to "measure the convergence among a set of items representing a latent construct and to define the extent to which the variables are consistent in their values" [8, 27, 29].

Table 1 shows the results of the convergent validity and reliability analysis. It can be noticed that all standardized factor loadings are statistically significant and their values are higher than 0.5, showing that the indicators reflect the corresponding latent variable almost perfectly. AVE shows the explained variance of the construct. All AVE values are higher than 0.5, therefore confirming the strong convergent validity of the constructs $[8,29]$. Cronbach's alpha coefficients were used for the reliability analysis. Acceptable values for these coefficients are mostly in the range from 0.70 to 0.95 , whereas some researchers consider the value of 0.60 adequate [27]. Cronbach's alpha coefficients for all constructs are above the threshold of 0.7 , indicating an internal consistency of the items.

\begin{tabular}{|c|c|c|c|c|}
\hline Factor & Item* & $\begin{array}{l}\text { Standardized } \\
\text { factor loading }\end{array}$ & AVE & $\begin{array}{c}\text { Cronbach's } \\
\text { alpha }\end{array}$ \\
\hline \multirow{6}{*}{$\begin{array}{l}\text { Financial } \\
\text { behavior (FB) }\end{array}$} & FB1 & $0.523^{* *}$ & \multirow[t]{6}{*}{0.512} & \multirow[t]{6}{*}{0.802} \\
\hline & FB2 & $0.648^{* *}$ & & \\
\hline & FB3 & $0.742^{* *}$ & & \\
\hline & FB4 & $0.572^{* *}$ & & \\
\hline & FB5 & $0.839^{* *}$ & & \\
\hline & FB6 & $0.893^{* *}$ & & \\
\hline \multirow{3}{*}{$\begin{array}{l}\text { Financial } \\
\text { security (FS) }\end{array}$} & FS1 & $0.841^{* *}$ & \multirow[t]{3}{*}{0.720} & \multirow[t]{3}{*}{0.849} \\
\hline & FS2 & $0.922^{* *}$ & & \\
\hline & FS3 & $0.776^{* *}$ & & \\
\hline \multirow{6}{*}{$\begin{array}{l}\text { Self-control } \\
(\mathrm{SC})\end{array}$} & SC1 & $0.549^{* *}$ & \multirow[t]{6}{*}{0.500} & \multirow[t]{6}{*}{0.798} \\
\hline & $\mathrm{SC} 2$ & $0.714^{* *}$ & & \\
\hline & SC3 & $0.712^{* *}$ & & \\
\hline & $\mathrm{SC} 4$ & $0.802^{* *}$ & & \\
\hline & SC5 & $0.712^{* *}$ & & \\
\hline & SC6 & $0.726^{* *}$ & & \\
\hline \multirow{3}{*}{$\begin{array}{l}\text { Optimism } \\
\text { (OPT) }\end{array}$} & OPT1 & $0.792^{* *}$ & \multirow[t]{3}{*}{0.625} & \multirow[t]{3}{*}{0.788} \\
\hline & OPT2 & $0.787^{* *}$ & & \\
\hline & OPT3 & $0.792^{* *}$ & & \\
\hline \multirow{4}{*}{$\begin{array}{l}\text { Deliberative } \\
\text { thinking (DT) }\end{array}$} & DT1 & $0.841^{* *}$ & \multirow[t]{4}{*}{0.702} & \multirow[t]{4}{*}{0.873} \\
\hline & DT2 & $0.797^{* *}$ & & \\
\hline & DT3 & $0.829 * *$ & & \\
\hline & DT4 & $0.883^{* *}$ & & \\
\hline \multirow[t]{4}{*}{ Intuition (INT) } & INT1 & $0.774^{* *}$ & \multirow[t]{4}{*}{0.652} & \multirow[t]{4}{*}{0.843} \\
\hline & INT2 & $0.907^{* *}$ & & \\
\hline & INT3 & $0.772^{* *}$ & & \\
\hline & INT4 & $0.769^{* *}$ & & \\
\hline
\end{tabular}


*FB1 - "I comparison shop when purchasing a product or service"; FB2 - "I pay all my bills on time"; FB3 - "I stay within my budget or spending plan"; FB4 - "I began or maintained an emergency savings fund"; FB5 - "I save money from every paycheck"; FB6 "I save for a long term goal such as a car, education, home, etc."; FS1 - "I feel secure in my current financial situation"; FS2 - "I feel confident about my financial future"; FS3 - "I feel confident about having enough money to support myself in retirement, no matter how long I live"; SC1 - "I get distracted easily"; SC2 - "I do things that feel good in the moment but regret later on"; SC3 - "I often act without thinking through all the alternatives"; SC4 - "I only focus on the short term"; SC5 - "The future will take care of itself"; SC6 - "I live more for the day of today than for the day of tomorrow"; OPT1 - "If something can go wrong for me, it will"; OPT2 - "I hardly ever expect things to go my way"; OPT3 - "I rarely count on good things happening to me"; DT1 - "Developing a clear plan is very important to me"; DT2 - "I like to analyze problems"; DT3 - "I prefer well-prepared meetings with a clear agenda and strict time management"; DT4 - "I usually have clear, explainable reasons for my decisions"; INT1 - "When I make a decision, it is more important for me to feel the decision is right than to have a rational reason for it"; INT2 - "When I make a decision, I trust my inner feeling and reactions"; INT3 - "I prefer drawing conclusions based on my feelings, my knowledge of human nature, and my experience of life"; INT4 - "I hardly ever go wrong when I listen to my deepest gut feelings to find an answer".

* Significant at 0.01 level

Table 1: Convergent validity and reliability for the constructs

The results of discriminant validity testing can be found in Table 2. The table represents the correlation matrix between the latent constructs. The values on the diagonal show the square root of each AVE, which are compared to the correlation coefficients for each construct in the relevant rows and column. All of these values have a greater value than the correlations with other constructs. Thus, discriminant validity is supported [8, 29].

\begin{tabular}{|l|l|l|l|l|l|l|}
\hline & \multicolumn{1}{|c|}{ FB } & \multicolumn{1}{|c|}{ FS } & SC & OPT & DT & \multicolumn{1}{|c|}{ INT } \\
\hline FB & $\mathbf{0 . 7 1 6}$ & & & & & \\
FS & 0.532 & $\mathbf{0 . 8 4 8}$ & & & & \\
SC & 0.382 & 0.280 & $\mathbf{0 . 7 0 7}$ & & & \\
OPT & 0.184 & 0.136 & 0.492 & $\mathbf{0 . 7 9 0}$ & & \\
DT & 0.441 & 0.248 & 0.314 & -0.095 & $\mathbf{0 . 8 3 8}$ & \\
INT & 0.248 & 0.115 & -0.097 & -0.153 & 0.602 & $\mathbf{0 . 8 0 8}$ \\
\hline
\end{tabular}

Table 2: Discriminant validity of the constructs

\subsection{Structural equation modeling and mediation testing}

As already stated, there are several latent constructs in the model: FB, FS, SC, OPT, DT, and INT. Each of the constructs is measured through a number of variables, which are represented by the corresponding survey questions, which are given in Table 1 . The answers to these questions are formulated as a level of agreement with the given statements on a 1-5 Likert scale. Considering that the Likert scale is an ordinal type of variable, the mean and variance adjusted weighted least squares (WLSMV) method of estimation is used [11]. The model consists of six latent constructs and 26 indicators. It has 287 degrees of freedom, making it overidentified and suitable for further analysis. Unit loading identification (ULI) constraints were imposed to achieve model identification, as is usual, which means that one unstandardized coefficient for each construct is fixed to equal one [11].

The majority of model fit statistics, seen in Table 3, show acceptable fit, except for the Chi-square test, which yields a significant result. However, this criterion is rarely satisfied with 
larger sample sizes (over 200), because the Chi-square value increases along with the sample size $[5,7,8,9,11,17]$. Hence, considering the limitation of the Chi-square test and other acceptable fit statistics values, the model is retained.

All standardized estimates for the hypothesized paths of the model are statistically significant, except for the path from INT to FB. Therefore, it is found that SC and other psychological characteristics of individuals, except for INT, positively and significantly affect FB. Moreover, $\mathrm{SC}$ has a positive significant impact on FS as well. The highest impact is the one from FB to FS. Thus, it can be concluded that higher self-control, more optimism and a higher tendency for deliberative thinking lead to better financial behavior, i.e. people with those characteristics are more likely to save and not get into debt. Higher self-control and more disciplined financial behavior lead to higher financial security.

In order to test the research hypothesis, it is necessary to test for mediation. A mediating effect exists if a third construct intervenes between two other related constructs [8]. Firstly, it can be seen that SC significantly affects both FS and FB, while FB also significantly affects FS. The direct effect from SC to FS is 0.090 (p-value 0.038), while the indirect effect is equal to 0.116 (the product of the paths from SC to FB and from FB to FS; p-value 0.001). The total effect of SC on FS is the sum of the direct and indirect effects and it is equal to 0.207 ( $p$-value $\leq 0.001$ ). In a previously tested model, with no mediator between SC to FS included, the path coefficient from SC to FS was 0.098 and it was significant. Therefore, since this path coefficient lessened, but remained significant when the mediator FB was included, it can be concluded that partial mediation is supported [8]. To measure the proportion of the total effect that is operating through the mediator, a ratio of the indirect to the total effect is calculated. It is found that $56 \%$ of the total effect of self-control on financial security is due to good financial behavior.

Thus, the research hypothesis is supported: Financial behavior mediates the relationship between self-control and financial security.

\begin{tabular}{|l|l|l|}
\hline Hypothesized path & Standardized estimates & \multicolumn{1}{|c|}{ p-value } \\
\hline $\mathrm{SC} \rightarrow \mathrm{FB}$ & 0.234 & 0.001 \\
\hline $\mathrm{OPT} \rightarrow \mathrm{FB}$ & 0.114 & 0.050 \\
\hline $\mathrm{DT} \rightarrow \mathrm{FB}$ & 0.322 & 0.000 \\
\hline $\mathrm{INT} \rightarrow \mathrm{FB}$ & 0.094 & 0.138 \\
\hline $\mathrm{SC} \rightarrow \mathrm{FS}$ & 0.090 & 0.038 \\
\hline $\mathrm{FB} \rightarrow$ FS & 0.498 & 0.000 \\
\hline$\chi^{2}=1007.171, \mathrm{p}-$ value $\leq 0.001$, RMSEA $(90 \%$ C.I. $)=0.071(0.067-0.076)$, \\
$\mathrm{CFI}=0.935$, TLI $=0.926$ \\
\hline
\end{tabular}

Table 3: Results of the structural model with goodness of fit measures

The path diagram of the final model with its standardized estimates is presented in Figure 1. Bold lines represent statistically significant paths. As already discussed, the only insignificant path is the path from INT to FB, which can clearly be seen in the path diagram below. 


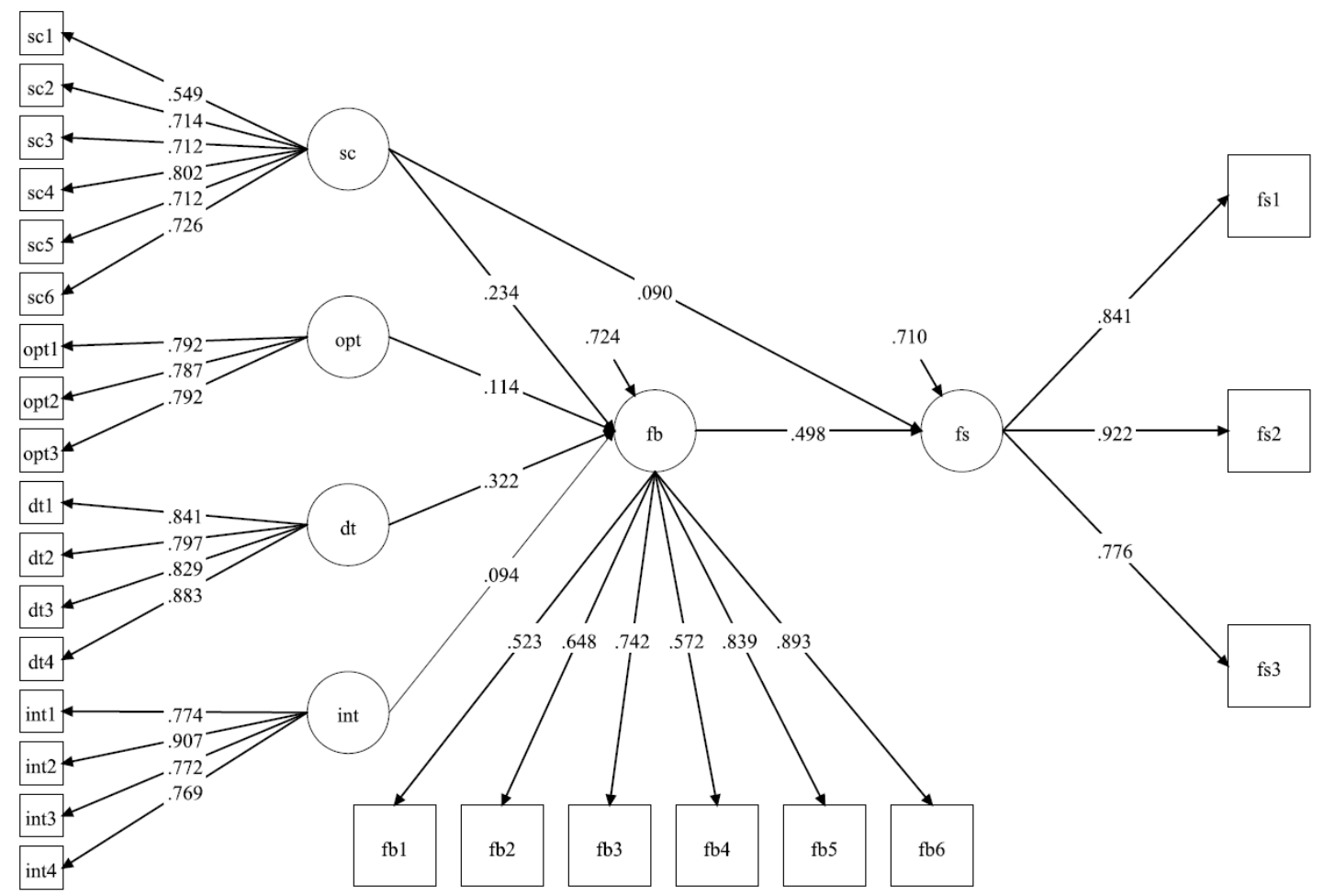

Figure 1: Path diagram with standardized estimates

\section{Conclusion}

The aim of this research was to explore if there is a mediating effect from SC to FS through FB. The data for the research was collected through a survey analysis. The final sample includes 494 respondents who are residents of Croatia.

Firstly, the results of the structural model indicate a positive influence of SC, OPT, and DT on FB. Specifically, it means that people with higher self-control, people who are more optimistic, and people prone to deliberative thinking will have better behavior in the context of finance. Therefore, these are psychological characteristics that influence people's tendency to save more money and manage their finances in better ways by not getting into debt. On the other hand, INT, which is practically the opposite of DT, has not been shown to have a significant impact on FB. In addition, SC positively affects FS, indicating that people with higher self-control have a more positive attitude towards their current and future financial security. More disciplined financial behavior also causes individuals to feel more secure about their finances.

The research hypothesis stated that financial behavior mediates the relationship between self-control and financial security. This was examined by testing for specific indirect effects compared to the previously tested model without the mediator between SC and FS. It was found that there is a significant mediating effect of $\mathrm{FB}$ on the relationship between $\mathrm{SC}$ and FS. Specifically, partial mediation is supported and it shows that $56 \%$ of the total effect of self-control on financial security is due to good financial behavior. These results confirm the research hypothesis.

The main limitation of this research is the fact that only an electronic form of the survey was used, so some demographic and social groups might be excluded and/or included unevenly. 
The research contributes to a better understanding of financial behavior predictors among individuals with different psychological characteristics. Future research can explore whether a model respecification can provide insights into self-control predictors. It should also include testing for differences between various cultures and demographic groups of people in the impact of self-control and other different psychological characteristics of individuals on financial behavior and security.

\section{References}

[1] Ab Hamid, M. R., Sami, W. and Mohmad Sidek, M. H. (2017). Discriminant Validity Assessment: Use of Fornell \& Larcker criterion versus HTMT Criterion. Journal of Physics: Conference Series, 890, 1-5. doi: 10.1088/1742-6596/890/1/012163

[2] Achtziger, A., Hubert, M., Kenning, P., Raab, G. and Reisch, L. (2015). Debt out of control: The links between self-control, compulsive buying, and real debts. Journal of Economic Psychology, 49, 141-149. doi: 10.1016/j.joep.2015.04.003

[3] Ameriks, J., Caplin, A. and Leahy, J. (2003). Wealth Accumulation and the Propensity to Plan. The Quarterly Journal of Economics, 118(3), 1007-1047. doi: 10.1162/00335530360698487

[4] Ameriks, J., Caplin, A., Leahy, J., Tyler, T., and Tyler, T. O. M. (2010). Measuring Self-Control Problems. The American Economic Review, 97(3), 966-972. doi: 10.1257/aer.97.3.966

[5] Awang, Z. (2012). A Handbook on SEM: Structural equation modeling using amos graphics, Kelantan: University Technology MARA Press.

[6] Fujita, K., Trope, Y., Liberman, N. and Levin-Sagi, M. (2006). Construal Levels and Self-control. Journal of Personality and Social Psychology, 90(3), 351-367. doi: 10.1037/0022-3514.90.3.351

[7] Gefen, D., Straub, D. and Boudreau, M.-C. (2000). Structural Equation Modeling and Regression: Guidelines for Research Practice. Communications of the Association for Information Systems, 4, Article 7. doi: 10.17705/1CAIS.00407

[8] Hair, J. F., Black, W. C., Babin, B. J. and Anderson, R. E. (2010). Multivariate Data Analysis. Pearson Prentice Hall: Upper Saddle River, NJ.

[9] Hooper, D., Coughlan, J. and Mullen, M. R. (2008). Structural Equation Modelling: Guidelines for Determining Model Fit. The Electronic Journal of Business Research Methods, 6(1), 53-60. https://arrow.tudublin.ie/buschmanart/2/

[10] Khoirunnisaa, J. and Johan, I. R. (2020). The Effects of Financial Literacy and Self-Control towards Financial Behavior among High School Students in Bogor. Journal of Consumer Sciences, 5(2), 73-86. doi: 10.29244/jcs.5.2.73-86

[11] Kline, R. B. (2011). Principles and Practice of Structural Equation Modeling. New York: The Guilford Press.

[12] Miotto, A. P. S. C. and Parente, J. (2015). Antecedents and consequences of household financial management in Brazilian lower-middle-class. RAE Revista de Administracao de Empresas, 55(1), 50-64. doi: 10.1590/S0034-759020150106

[13] Nachtigall, C., Kroehne, U., Funke, F. and Steyer, R. (2003). (Why) Should we use SEM? Pros and cons of structural equation modeling. Methods of Psychological Research Online, 8(2), 1-22. https://www.semanticscholar.org/paper/(Why)-Should-We-Use-SEM-Pros-and-Consof-Structural-Nachtigall-Kr

[14] Ottaviani, C. and Vandone, D. (2011). Impulsivity and household indebtedness: Evidence from real life. Journal of Economic Psychology, 32(5), 754-761. doi: 10.1016/j.joep.2011.05.002

[15] Pachur, T. and Spaar, M. (2015). Domain-specific preferences for intuition and deliberation in decision making. Journal of Applied Research in Memory and Cognition, 4(3), 303-311. doi: 10.1016/j.jarmac.2015.07.006

[16] Parise, G. and Peijnenburg, K. (2017). Understanding the Determinants of Financial Outcomes and Choices: The Role of Noncognitive Abilities. Bank for International Settlements. Working Paper No. 640. [Accessed 17/7/2020]

[17] Schreiber, J. B., Nora, A., Stage, F. K., Barlow, E. A. and King, J. (2006). Reporting Structural Equation Modeling and Confirmatory Factor Analysis Results: A Review. The Journal of Educational Research, 99(6), 323-337. doi: 10.3200/JOER.99.6.323-338 
[18] Shefrin, H. M. and Thaler, R. H. (1988). The Behavioral Life-Cycle Hypothesis. Economic Inquiry, 26(4), 609-643. doi: 10.1111/j.1465-7295.1988.tb01520.x

[19] Siswanti, I. and Halida, A. M. (2020). Financial knowledge, financial attitude, and financial management behavior: Self-control as mediating. The International Journal of Accounting and Business Society, 28(1), 105-132. doi: 10.21776/ub.ijabs.2020.28.1.5

[20] Strömbäck, C., Lind, T., Skagerlund, K., Västfjäll, D. and Tinghög, G. (2017). Does self-control predict financial behavior and financial well-being? Journal of Behavioral and Experimental Finance, 14, 30-38. doi: 10.1016/j.jbef.2017.04.002

[21] Strömbäck, C., Skagerlund, K., Västfjäll, D. and Tinghög, G. (2020). Subjective self-control but not objective measures of executive functions predicts financial behavior and well-being. Journal of Behavioral and Experimental Finance, 27, 100339. doi: 10.1016/j.jbef.2020.100339

[22] Strunk, D. R., Lopez, H. and DeRubeis, R. J. (2006). Depressive symptoms are associated with unrealistic negative predictions of future life events. Behaviour Research and Therapy, 44(6), 861-882. doi: 10.1016/j.brat.2005.07.001

[23] Sudindra, V. R. and Naidu, J. G. (2018). Financial Behaviour and DecisionMaking. International Journal of Creative Research Thoughts, 6(1), 1427-1435. https://ijcrt.org/papers/IJCRT1802182.pdf

[24] Sultan, A. J., Jeff Joireman, J. and \& Sprott, D. E. (2012). Building consumer self-control: The effect of self-control exercises on impulse buying urges. Marketing Letters, 23 (1), 61-72. doi: $10.1007 / \mathrm{s} 11002-011-9135-4$

[25] Teddlie, C. and Yu, F. (2007). Mixed Methods Sampling: A Typology With Examples. Journal of Mixed Methods Research, 1(77), 77-100. doi: 10.1177/1558689806292430

[26] Thoma, V., White, E., Panigrahi, A., Strowger, V. and Anderson, I. (2015). Good thinking or gut feeling? Cognitive reflection and intuition in traders, bankers and financial non-experts. PLoS ONE, 10(4), 1-17. doi: 10.1371/journal.pone.0123202

[27] Vuković, M., Pivac, S. and Kundid, D. (2019). Structural equation modeling in the acceptance of internet banking in the city of Split. Croatian Operational Research Review, 10(1), 141-152. doi: 10.17535 /crorr.2019.0013

[28] Younas, W., Javed, T., Ramanathan Kalimuthu, K., Farooq, M., Khalil-ur-Rehman, F. and Raju, V. (2019). Impact of Self-Control, Financial Literacy and Financial Behavior on Financial Well-Being. The Journal of Social Sciences Research, 5(1), 211-218. https://ideas.repec.org/a/arp/tjssrr/2019p211-218.html

[29] Zait, A. and Bertea, P. (2011). Methods for testing discriminant validity. Management \& Marketing Journal, IX(2), 217-224. https://econpapers.repec.org/article/aiomanmar/v_3aix_3ay_3a2011_3ai_3a2_3ap_3a217-224.htm 